\title{
Determinants of Brand choice of two wheelers in Kathmandu Valley
}

\author{
Sanita Mastran *
}

\begin{abstract}
Understanding of consumer buying behavior is difficult task as it is influenced by many factors such as cultural, social, personal and psychological. Understanding the consumer's lifestyle is necessary for the marketers. Consumer needs and preferences are changing due to the change in the factors like demographics and lifestyles. These changes can become great business opportunities for alert marketers and threats for those who fail to adapt. Demographic variables help marketers locate their target market and psychographic variables provide the marketer with more insight about the segment. Psychographics is in common lifestyle analysis or AIO (activities, interests and opinions) research.
\end{abstract}

The major objective is to empirically examine the relationship and impacts of demographic and psychographic variables with brand choice. A conceptual model has been tested with different determinants of demographic and psychographic variables to examine relationship with brand choice. In this study, Activities, Interests and Opinions (AIO) is used to identify lifestyle dimensions and demographic variables (age, education level, profession and Gender) as independent variables and brand choice (Innovation, quality, advertising, and price and reference group) as dependent variable. The results indicated that the lifestyle factors and demographic factors have impact on brand choice variables. The study shows that there was a significant association between the lifestyle of the consumers and the brands of products used by them. From the study it was concluded that consumers often choose products, services and activities over other because they are associated with a certain lifestyle.

Keywords: Demographic and Psychographic Determinants, lifestyle (AIO), Brand choice

* M.Phil. (Marketing Management), Faculty of management at Sea Bird International College, Tribhuvan University. 


\section{Introduction}

In this era of competition, understanding the consumer's lifestyle is necessary for the marketers. Lifestyle is the way a person lives including the person's individual attitude to the world. Lifestyle depends on person's background, family, education, and profession. Consumer needs and preferences are changing, given change the factors like demographics and lifestyles. These changes can become great business opportunities for alert marketers and threats for marketers who fail to adapt. Demographic variables help marketers to locate their target market and psychographic variables provide the marketer with more insight about the segment. Psychographics is, in common parlance, lifestyle analysis or AIO (Activities, Interests and Opinions) research. In its most widely practiced form, a psychographic study consists of a long list of statements designed to capture relevant aspects of a consumer, like personality, interests, attitudes, beliefs and values. The demographic and psychographic lifestyle approaches are highly complementary and work best together.

Lifestyle marketing is a process of establishing relationships between products offered in the market and targeted lifestyle groups. It involves segmenting the market on the basis of lifestyle dimensions, positioning the product in a way that appeals to the activities, interests and opinions of the targeted market and undertaking specific promotional campaigns which exploit lifestyle appeals to enhance the market value of the offered product. Life style patterns are a system concept that refers to a distinctive mode of living in its aggregate and broadcast sense, which embodies the patterns that develop and emerge from dynamism of living in a society (Lazer, 1963). Life style patterns provide a broader, three dimensional view of customer, so that one can think about relevant product positioning, communication, media and promotion. (Plummer, 1974). The most widely used approach to life style measurement has been AIO (Activities, interest, and opinions) rating statements. Life style as used in life style segmentation research measures:

1. People's activities, in terms of how they spend their time.

2. People's interests, what they place importance on in their immediate surroundings.

3. People's opinions, in the term of their view of themselves and the world around them.

The Objectives of the Study are: 
i) To examine the relationship of demographic and psychographic variables with brand choice variables. And

ii) To examine the impacts of demographic and psychographic determinants on Brand choice of two wheelers.

\section{Statement of problem}

The consumer is sovereign, deciding whether to accept or reject a product on the basis of whether or not it meets perceived needs and desires. However, understanding of consumer buying behavior is a complex and difficult task as it is influenced by many factors such as cultural, social, personal and psychological. In addition, consumer behavior is a changing phenomenon. Consumers' needs and desires undergo change from time to time. In order to adapt business with changing pace of consumers' needs and desires, it is essential for marketers to conduct research continuously on consumers. Realizing this fact, business enterprises of advanced countries have carried out a series of researches on consumer behavior. However, such practices of studying consumer buying behavior are rare in our country. Here, an attempt has been made to study the consumer behavior with respect to decision making process of motorbike purchase in Kathmandu city.

Hypotheses are developed to test the relationship between the psychographic - Lifestyle and Demographic determinants of brand choice of two wheelers.

H 1: Work and leisure activities are associated with Brand choice.

H 2: Consumer's interests are associated with the Brand choice.

H 3: Consumer's opinions are associated with Brand choice.

H4: Age is associated with Brand choice.

H5: Education level is associated with Brand choice.

H6: Profession is associated with Brand choice.

H7: Gender is associated with Brand choice. 


\section{Review of Literature}

\section{Lifestyle and Psychographics concepts}

The Lifestyle of individuals has always been of great interest to marketers. They deal with everyday behaviorally oriented facets of people as well as their feelings, attitudes, interests and opinion. The lifestyle concept was introduced by Bell (1958), Rainwater, Coleman and Handel (1959), and Havinhurst and Feigenbaum (1959) as close to 1950s, pointing to its potential significance in understanding, explaining and predicting consumer behavior. Wells provides this historical perspective in his exhaustive "Psychographics: A Critical Review" (1975) Starting with the classic study of Koponen (1960), investigators have repeatedly tried to correlate consumer behavior with scores obtained from standardized personality inventories. And, starting with Dichter's innovative studies of consumers' motivations (1963), students of the consumer's mind have tried to apply the concepts and methods of clinical psychology to virtually every aspect of marketing.

During the 1960's a blend of these two traditions began to take shape. Variously called "lifestyle", "psychographic", or "activity and attitude" research, this blend combines the objectivity of the personality inventory with the rich, consumer-oriented, descriptive detail of the qualitative motivation research investigation. It is noteworthy that nowhere in Wells' article did he define or attempt to distinguish "lifestyle" from "psychographic" and "activity and attitude" research. Wells (1974) attempted to delimit and distinguish the domains of lifestyle from psychographic research. The term "psychographics" refers to studies that place comparatively heavy emphasis on generalized personality traits. Analysts who have preferred the term "lifestyle", on the other hand, have tended to focus either on broad cultural trends or on needs and values thought to be closely associated with consumer behavior.

The distinction has apparently been lost on most consumer analysts, as the terms continue to be used interchangeably, indeed by Wells himself (Wells, 1975). As lifestyle analysis entered its adolescent phase of development in the marketing literature at the dawn of the 1970, Dorny (1971) sought to distinguish psychographics from lifestyle research by: reserving the term "psychographics" for measures that are truly "mental" -attitudes, beliefs, opinions, personality traits, etc. The analysis and classification of activity or behavioral reports from the consumer which are frequently classified as 
"psychographics", should be given their own distinct term, such as "lifestyle" .While Dorny's conceptual distinction, too, has apparently fallen on deaf ears, it at least recognizes a potential, if imperfect, symmetry between what he refers to as "mental" processes or properties (the province of psychographic research) and overt activities or behavior (the domain of lifestyle research). Still, the terms psychographics and lifestyle remain largely undefined and indistinguishable in the marketing literature. William Lazer introduced the concept of lifestyle patterns and its relationship to marketing, in 1963. Lifestyle segmentation has been a very useful concept for marketing and advertisement planners. (Wells and Tigert, 1971) By incorporating psychographics' information with demographics, the marketer will better understand the wants and needs of the consumers. Psychographics was a term first introduced by Demby (1974) putting together psychology and demographics. Psychographic or Lifestyle refers to consumers' Activities Interests and Opinion (AIO). More specifically it focuses on what people like to do, what are their areas of interests, and what the opinion people hold on various matters. (Lazer, 1963, Plumer 1974). Hence lifestyle patterns provide broader views about the consumers. The basic premise of lifestyle research is that the more the marketers know and understand their customers, the more effectively they can communicate and serve them. (Kaynak and Kara, 1996).This study used the lifestyle analysis to identify market segments. The main purpose of this study is to empirically examine the association between the consumers' general life styles and their consumption patterns.

Lifestyle analysis is also used to build the lifestyle profiles of specific segments like working women, (Burns and Foxman 1988), women shopping behaviour (Robertz and Wortze, 1979). Reynolds, Crask and Wells (1977) analyzed the lifestyle differences of women with modern orientation and women of traditional orientation. Reynolds and Wells (1978) applied life style analysis for market segmentation, the development of product strategy and the development of the most appropriate communication strategy. The studies of Lazer (1963) and Jones (1982), indicate that lifestyle analysis is important in formulating marketing strategy. Forrest and Blumberg (1981) viewed the life style as a principle which allowed management to assess accurately the needs of relevant market segment because demographic descriptions have proved inadequate for this task. Ahmed and Jackson (1979) also confirmed that life style analysis could be of tremendous value to marketing managers. It facilitated the reduction of a large, heterogeneous population into a few basic groups. Product decisions are also influenced by life style patterns. Blackwell and Talarzyk (1983) noted that successful retailers based on general 
application of life style analysis have begun to implement a portfolio management approach which focuses on the needs of the key target markets. Blackwell (1980) and Mitchell (1983) stated that life style analysis could be used to monitor changes in the population. Aaker et al., (1982) endorsed the wide application of life style data and confirmed its use in promotion. For Berry (1983) life style segmentation provided a valuable insight into the task of creating an effective brand identity. The study of lifestyle often provides fresh insights into the market and gives a more three dimensional view of the target consumers. The marketing managers may be able to develop improved multidimensional views of key market segments, uncover new product opportunities, obtain better product position, develop improved advertising communications based on a richer more life-like portrait of the target consumer and generally improve overall marketing strategy. Rao and Natarajan (1996) examined the ownership and purchasing patterns of Indian consumers. Vera and Hanspal (2000) used lifestyle analysis to profile the middle class consumers of Delhi. Jain and Dhingra (1999) used fashion lifestyles to segment the young consumers of India. SeemaKapur (1995) tried to understand the relationship between ownership of two wheelers and behaviour of their owners. Adite Chaterjee (1995) conducted a study to understand the brand association of denim brands with lifestyle attributes. Shirali and Singh (1997) carried out a study to segment men into various lifestyle groups based on their status symbol. Kumar and Mitra (2004) segmented the Kolkata market into five groups based on their toothpaste brand choice. Similarly studies were carried by Roy and Goswami (2007) to understand the effect of psychographics.

\section{Demographics}

Demographics alone do not give a complete picture of the consumer, thus hampering the marketer in segmenting the market to its full potential (Cooper, 1984). Bone (1991) indicates that the use of demographic characteristics such as age, income and employment status can be misleading factors while segmenting markets. The use of chronological age as a tool for segmentation is not as closely related to purchase behavior as the psychological age (Barak \& Rahtz, 1989; Barots, 1980). Though income is highly related to buying behavior, it is generally used in segmenting the market; but it does not take into consideration factors such as activities, interest, health (Bone, 1991; Burnett \& Wilkes, 1985-86; Moehrle, 1990). Social class adds a greater depth to demographics but it has to be supplemented by other information to give a meaningful insight of the individual characteristics. 
The demand for the two wheelers in Nepal has grown enormously. The two wheeler users are influenced mainly by demographic variables. Demography refers to the vital and measurable statistics of a population. The demographic variables are the personal characteristics such as age, gender, marital status, educational qualification, occupation, type of family, number of members and annual income. They are the most popular bases for distinguishing customer groups. Hence, it is necessary to study the influence of demographic variables on the brand choice of two wheelers.

Demographic variables are social categories for individuals. Demographic variables can refer to social systems as well as individuals. An example of such a variable with a social unit of analysis is the existence or non-existence of a trade union for an organization. The nature of demographic variables must be more carefully examined. Occupation is a widely used example of these variables. The demographics information gathered in this study include age, education, occupation and gender and relationship of these variables are measured with brand choice.

Age is important demographic factor. Older people make a buying decision on the basis of their experience and value of satisfaction which they perceive by utilizing the product and service; however the young people do not rely on the satisfaction which they perceive from the product or service they also get information from the sale personnel and then make final buying decision. With the passage of time the need and preferences of the consumers have been changed, young people spend on fast food normally and old people spend on the products and services related to their health.

\section{Brand Choice}

One definition for a brand has been offered in the Journal of Marketing Management by Professor Peter Doyle of Warwick University: "A name, symbol, design, or some combination which identifies the product of a particular organization as having a substantial, differentiated advantage" A brand suggests the best choice, while others see a brand as something the customer knows and will react to. Organizations develop brands as a way to attract and keep customers by promoting value, image, prestige, or lifestyle. By using a particular brand, a consumer can cement a positive image. Brands can also reduce the risk consumers face when buying something that they know little about. Branding is a technique to build a sustainable, differential advantage by playing on the nature of human beings. Only humans can attach meaning and feeling to inanimate 
objects and a random collection of symbols, which suggests the appeal of branding which is not entirely rational . Once consumers become accustomed to a certain brand, they do not readily accept substitutes. As brand equity has emerged as a business priority and marketing imperative, so too has the need to understand and manage brand associations. The result has been the development of conceptual models of branding by academics and practitioners. While these models have been beneficial in simplifying brand complexity into a manageable number of components, they are inconsistent in their terminology, brand element segmentation, weighting assigned to specific elements, and relationships between the elements.

Disparities arising through differences in conceptual segmentation and weightings, and terminology aside, these models have made a significant contribution to our general understanding of branding issues. However, these branding models largely are a result of the synthesis of information gained from the experiences and perceptions of brand practitioners. Although valuable information can be gained by understanding brands through those who work closely with them, (brand managers and consultants) the true significance of brands can only be seen through the eyes of the beholder, i.e. the consumer. Consequently, the effectiveness of marketing stimuli becomes subservient to consumer brand knowledge residing in the minds of consumers, thus highlighting the importance of understanding the brand knowledge construct.

The main purpose of the study is to examine the lifestyle dimensions and its impact on brand choice of two wheelers in Nepal and to explore the impact of life style dimensions and demographic characteristics.

\section{Conceptual Framework}

The purpose of this study is to present and test a model that with different determinants of demographic and psychographic variables to examine relationship with brand choice of two wheelers. The major research questions addressed by this study are: (a) what is relationship between life style dimensions and brand choice? (b) What is relationship between demographic characteristics and brand choice variables? and (c) is life style clustered in relation to brand choice? 


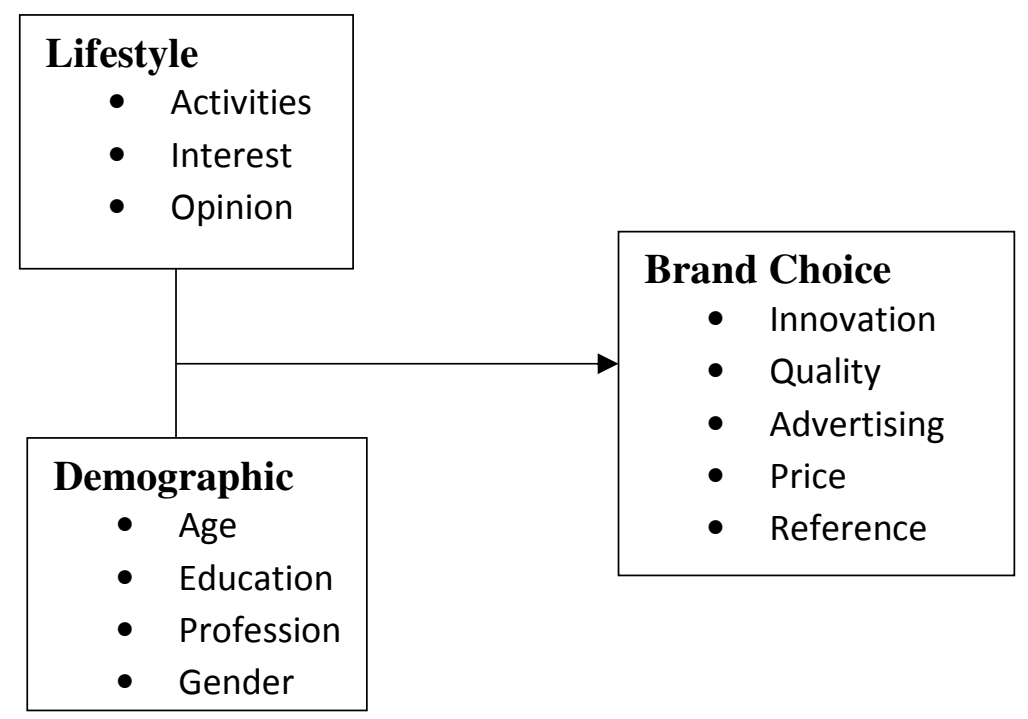

The conceptual model has been developed to empirically test the relationships among the variables that appear to be relevant to the present study. This model is based on the discussion and literatures reviewed .This model suggests that life style impacts on brand choice behavior of consumer. The relationship is examined by measuring Karl Pearson's Chi-square Test among the life style dimensions Activities, Interests and Opinions with brand choice variables and demographic with brand choice. Thus the model introduces life style (AIO) and demographic variables (age, education level, profession and Gender) as independent variables and brand choice (Innovation, quality, advertising, and price and reference group) as dependent variable.

\section{Data Collection Procedure and Research Methodology}

In this study, for the primary data collection, the questionnaire method is adopted to collect the data from different profession and different age group having two wheelers. Judgmental and convenient sampling technique was followed to gather the opinions of the respondents. Structured questionnaire method supplemented and unstructured interviews were extensively used in gathering necessary inputs for the study. Each of the questioners distributed consists of demographic, psychographic -lifestyle (AIO) and brand choice factors. The demographic section comprises of Age, Gender, Education Level and Occupation. All the questions are closed ended for the purpose of collecting appropriate data. In the questionnaire the respondents were requested to provide their opinions on the four point likert scale to measure their response. The four numbers 1 strongly disagree, 2 disagree, 3 agree and 4 strongly agree were used to measure response. 


\section{Statistical Tools and Techniques for Data Analysis}

Descriptive analysis was done by summating likert items of dependent and independent variables The study has used Cronbach's alpha to measure the internal reliability of the each variable of their related questionnaire. Simple descriptive statistical tools such as frequencies, mean and standard deviation were used as statistical tools. Karl Pearson's chi -Square test was done to test the association among the dependent and independent variables. Mean, standard deviation minimum and maximum analysis are used. The higher mean value indicate more respondents agree to the variables could have a great association or impact on brand choice of two wheelers. By analyzing the mean and standard deviation of variables, it indicates that a significantly large value of standard deviation the data being tested is far away from the mean from the minimum and maximum value whereas a smaller value indicates that the tested variable is closer to mean.

Analysis of result is based on 50 questionnaires as per sample size determined for undertaking the study. Out of 50 respondents, 28 respondents (56\%) were male and 22 (44\%) were female, indicating that the percentage of male and female respondents are almost equal. In terms of age group, majority of the respondents were under the age of 21-30 years (54\%) and 31-40 represent the (32\%). An attempt was also made to categorize the respondents on the basis of Education .In terms of education, majority respondents were bachelor passed (40\%) and $28 \%$ were $10+2$ pass out.

\section{Findings}

The results indicated that the following lifestyle factors and demographic factors have impact on brand choice variables. It also shows the association between the following independent and dependent variables.

- Consumers' interest and innovation

- Consumers' opinions and reference

- Age and innovation

- Education and price

- Profession and price 


\begin{tabular}{|l|l|c|c|l|}
\hline \multicolumn{1}{|c|}{ Association } & \multicolumn{1}{|c|}{ Value } & df & $\begin{array}{c}\text { Asymp. Sig. } \\
\text { (2-sided) }\end{array}$ & \multicolumn{1}{|c|}{ Result } \\
\hline Interests with Innovation & 256.661 & 204 & 0.007 & Significant \\
\hline Interests with Advertising & 225.705 & 187 & 0.028 & Significant \\
\hline Opinions with Reference & 226.944 & 176 & 0.006 & Significant \\
\hline Age with Innovation & $53.191^{\mathrm{a}}$ & 36 & .032 & Significant \\
\hline Education with Price & $65.030^{\text {a }}$ & 44 & 0.021 & Significant \\
\hline Profession with Price & $278.214^{\text {a }}$ & 220 & 0.005 & Significant \\
\hline
\end{tabular}

The Table shows the association between lifestyle factors, demographic factors and each brand choice factors as perceived by the respondents. Karl Pearson chi-square test has been used to measure the association between these variables

The research reports and evidences clarify that lifestyle and demographic variables have low associations with brand choice behavior. This approach was a significant moderate for consumers' brand choice behavior. This was not always possible that the lifestyle and demographic is associated with brand choice. The results of this study show that the demographics have an impact on innovation and price factors of brand choice. The result shows that low age consumer try new model of two wheelers and they frequently change the models. Age factor also impacts on the way of riding and the challenges of riding the two wheelers. This research work clarifies that consumers' interest impact on the innovation of the product. Also, their opinions and reference have association. The results found that age and innovation factors are associated with brand choice. This study also concludes that education level of consumer impacts on price of two wheelers. Educated consumers always compare the price, visit the showrooms and ask for discounts, free coupons, gifts etc. before purchasing two wheelers. Nepalese customers are price sensitive but their profession and price have significant association.

\section{Discussion}

This study has been carried out to examine the impacts of demographic and psychographic determinants of Brand choice of two wheelers. The variables have been classified as independent and dependent based on which theoretical framework has been developed. To fulfill the research objectives, a set of research questions was developed for collecting opinions and the research hypotheses have been made to explore the opinions of respondents. The questionnaires were distributed to respondents of different 
age group and different social class from various professions. The relationship was examined by measuring Karl Pearson's Chi-square Test among the life style dimensions Activities, Interests and Opinions with brand choice variables and demographic factors with brand choice variables. Thus the model introduces life style (AIO) and demographic variables (age, education level, profession and Gender) as independent variables and brand choice (Innovation, quality, advertising, and price and reference group) as dependent variable.

Survey questionnaire has been developed based on literature review and analysis of data has been carried out by analyzing the Cronbach alpha i.e. more than 0.70. Demographic, descriptive and chi-square test has been conducted for analyzing and interpreting data.

\section{Implications}

This study is basically about the factors that affect the brand choice behavior of two wheelers. The demand of two wheeler is rapidly increasing nowadays due to the consumer lifestyle and change in income, education level, standard of living etc. Two wheelers become a common need to most people in urban area and rural area of Nepal nowadays as it is one of the most convenient means of transportation. Consumers prefer two wheelers in comparison to other vehicles, as it is economical, easy handling, and suitable for narrow roads of Nepal. Consumer also buys two-wheelers for pleasure and as a solution for traffic jam inside the Valley.

The research reports and evidences clarify that lifestyle and demographic variables have low association with brand choice behavior. The results of this study show that the demographics have an impact on innovation and price factors of brand choice. The result shows that low age consumer try new model of two wheelers and they frequently change the models. Age factor also impacts on the way of riding and the challenges of riding the two wheelers. This study also concludes that education level of consumer impacts on price of two wheelers. Educated consumers always compare the price, visit the showrooms and ask for discounts, free coupons, gifts etc. before purchasing two wheelers. Nepalese customers are price sensitive but their profession and price have significant association. 


\section{REFERENCES}

Aaker A, David, Y. F. and Fred D. R. (1982). Is Life Style Research Limited in Its Usefulness to Japanese Advertisers, Journal of Advertising, 11, 31-36 and 48.

Ahmed, S. A. and Douglas N. J. (1979). Psychographics and Public Policy Decisions: Welfare Assistance, Journal of Consumer Research, 5, 229-239.

Barak, B. and Rahtz, D. R. (1989). Cognitive Age and Youthfulness: Demographic and Psychographic Dimension, in Advances in Health Care Research (Eds) R. E. Kriner \& G. T. Baker, III, Silver Springs, MD, American Association for Advances in Health Care Research, 47-51

Bartos, R. (1980). The Invisible Consumer Market, Harvard Business Review, 58.

Bell, W. (1958). Social Choice, Life Style , and Suburbal Residence, in Rhe Suburban Community (ed.) William M Dobriner, G.P. Putnam's Sons, New york, pp. 225242

Berry, E. J. (1983). Ads Enlist Ambiguity to Target varied Life styles, values, Ad Forum, $4,10-11$.

Black, R. D. and Wayne, T. W. (1983). Life style Retailing: Competitive strategies for the 80s, Journal of Retailing, 59, 7-27.

Black, W. and Roger, D. (1980). Successful Retailers of '80s will cater to specific Life style segments, Marketing News, 3, 3.

Bone, P. F. (1991). Identifying Mature Segments. The Journal of Services Marketing, 5, 47-60.

Boyd, H. W. Jr and Sidney J. Levy. (1967) Promotion: A behavioral View. Prentice Hall Publication: Englewood Cliffs, N.J.

Burnett and W. R. (1985/86.) An Appraisal of the Senior Citizen Segment. Journal of Retail Banking, 7.

Burns, A. C. and Ellen, R. F. (1989). Some Determinants of the Use of Advertising by Married Working Women. Journal of Advertising Research, 29, 57-58 
Chatterji, A. (1995). Marketing to New Indian Consumer of Generation I, Business Today.

Cooper, P. D. (1984). Elderly Segmentation: A Factor Analytic Approach to Psychographics Segmentation in Proceedings of the Annual Meeting of the Southern Marketing Association (Eds) D. M. Klein \& A. E. Smith.

Darden, W. R. and Fred D. R. (1974). Backward Profiling of Male Innovators, Journal of Marketing Research, 11, 79-85.

Dichter, Ernest (1964), Handbook of Consumer Motivations, New York: McGraw-Hill.

Dorny, L. R. (1971). Observations on Psychographics in Attitude Research Reaches New Heights, eds. Charles W. King and Douglas i. Tigert, Chicago. American Marketing Association, 200-201.

Forrest, E. J. and Leo B. (1981). Mailing list Psychographics: An inside Look for Prospects, Direct Marketing, 4, 458-61. 297.

Fred D. R. and William R. D. (1972). An operational Construction of Life Style, in Proceedings of the Annual Conference of the Association of Consumer Research, pp. 482.

Havighurst, R. J. and Feigenbaum, K. (1959). Leisure and Life Style, American Sociologist, 64, 396-404.

Jones, M. D. (1982) Properly Applied Psychographics Add Marketing Luster. Marketing News, 16 November 12, 10.

Joseph, T. P. (1974). The Concept and Application of Life Style Segmentation. Journal of Marketing, 38, 33-37.

Kapur, S. (1995). Lifestyle on Two Wheels Business World. Toothpaste usage and consumption profile, Organizational Management, 20, 5-11.

Koponen, A. (1960). Personality Characteristics of Purchasers. Journal of Advertising Research, 1, 21 (September), 6-12.

Lazer, W. (1963). Symbolism and Life Style, in Toward Scientific Marketing (Ed.) Stephen A. Greyser. American Marketing Association, Chicago, II, pp. 140-149. 
Mitchell, A. (1983). Styles in the American Bullring, Across the Board, 20, 45-54.

Moehrie, T. (1990). Expenditure Patterns of the Elderly. Monthly Labour Review, 34-41.

Moore, D. G. (1963). Lifestyle in Mobile Suburbia, in Towards Scientific Marketing (Ed.) Stephen A Greyser, American Marketing Association, Chicago, 2, 243-266.

Rainwater, L. Richard P. C. and Gerald H. (1959). Workingman's Wife. Oceans Publications: New York. The New Market Place, Business Today, 83-93.

Reynolds, F. D., Melvin, R. C. and William D. W. (1977). The Modern Feminine Life Style. Journal of Marketing, 38-45.

Roberts, M. L. and Lawrence H. W. (1979). New Life Style Determinants of Women's Food Shopping Behavior, Journal of Marketing, 43, 28-39.

Roy, S. and Goswami, P. (2007). Psychographics and Its Effect on Purchase FrequencyA Study on College Goers of Kolkata, India. International Journal of Economics and Management..

Shirali, A. and Iqbal S. (1997). Status Symbols an A \& M, ORG-MARG Survey. Advertising and Marketing. Journal of Consumer Research, 8, 452-455.

Wells, W. D. (1968). Backward Segmentation in Insights into Consumer Behavior, ed. J. Arndt, New York: Allyn and Bacon, 85-100.

(1974). Life Style and Psychographics: Definitions, Uses and Problems in Life Style and Psycho- graphics, ed. William D. Wells, Chicago, IL: American Marketing Association, 317-363.

(1975). Psychographics: A Critical Review. Journal of Marketing Research, 12, 196-213.

and Tigert, D. J. (1971). Attitudes, Interests and Opinions. Journal of Advertising Research, 11, 27-35.

William L. (1963). Life style Concept and Marketing Towards Scientific Marketing in American Marketing Ass.(Ed.). 